\title{
Valve-sparing procedure and Lecompte maneuver in patients with late aortic regurgitation and aortic aneurysm after the arterial switch operation
}

\author{
Yih-Sharng Chen, MD, PhD, Ing-Sh Chiu, MD, PhD, Shu-Chien Huang, MD, and Shyh-Jye Chen, MD, \\ Taipei, Taiwan
}

Aortic regurgitation and root dilatation can develop during long-term follow up after the arterial switch operation (ASO). ${ }^{1}$ Despite the fact that few patients required surgical reintervention, significant regurgitation was still an important cause of late mortality. ${ }^{1,2}$ Aortic valve replacement with or without a graft was the most common procedure.

The aortic valve-sparing operation was first described by David and Feindel ${ }^{3}$ more than a decade ago in patients with aortic aneurysms. Now extended criteria and results in other categories encourage us to apply the technique in patients with aortic root dilatation and regurgitation late after the ASO.

\section{CLINICAL SUMMARY}

A male baby was given a diagnosis of Taussig-Bing anomaly, double-outlet right ventricle, subpulmonary ventricular septal defect, and coarctation of the aorta at 45 days of age, presenting with cyanosis. Palliative balloon atriotomy was performed, followed by extended end-to-end aortoplasty and pulmonary artery banding 1 week after. He underwent debanding of the main pulmonary artery, ventricular defect repair, and the ASO with the Lecompte maneuver at 3 months of age without complication.

An echocardiographic series revealed progressive dilatation of the neoaortic root and aortic regurgitation (moderate to severe) since 3 years after the ASO. Computed tomographic analysis at 8 years of age demonstrated a dilated aortic root $(51 \mathrm{~mm})$, ascending aortic aneurysm, significant left ventricular outflow (LVOT) obstruction, coarctation distal to the left carotid artery, and distorted left pulmonary artery by the dilated aortic root (Figure 1). Catheterization reconfirmed the pressure gradient at the left ventricle outflow up to $70 \mathrm{~mm} \mathrm{Hg}$, arch coarctation, and moderate subpulmonary stenosis. Because of the progressive regurgitation and dilated aortic aneurysm, surgical intervention was arranged.

\footnotetext{
From the Department of Cardiovascular Surgery, National Taiwan University Hospital, Taipei, Taiwan.

Disclosures: None.

Received for publication April 6, 2010; revisions received May 18, 2010; accepted for publication June 2, 2010; available ahead of print July 2, 2010.

Address for reprints: Yih-Sharng Chen, MD, PhD, Department of Cardiovascular

Surgery, National Taiwan university Hospital, 7 Chung-Shan S Rd, 100, Taipei,

Taiwan (E-mail: yschen1234@gmail.com).

J Thorac Cardiovasc Surg 2010;140:1191-2

0022-5223/\$36.00

Copyright $₫ 2010$ by The American Association for Thoracic Surgery

doi:10.1016/j.jtcvs.2010.06.001
}

After careful resternotomy, a 6-mm polytetrafluoroethylene graft was anastomosed to the brachiocephalic artery as aortic inflow, and bicaval cannulation was performed to initiate cardiopulmonary bypass. The aorta and pulmonary artery were carefully dissected. Cardiac arrest was induced with cardioplegic solution through individual cannulation of the coronary ostia after aortic clamping and transection. The arch was opened and augmented with Hemashield during deep hypothermia $\left(20^{\circ} \mathrm{C}\right)$ with antegrade cerebral perfusion $(200 \mathrm{~mL} / \mathrm{min})$ through the brachiocephalic artery. The pulmonary artery was transversely amputated, and the hypertrophic muscle at the right ventricular outflow tract was excised to release the subpulmonary obstruction.

The aortic root down to the annulus was carefully dissected and mobilized. The pulmonary artery was translocated backward to restore its native relationship (the Lecompte maneuver). The coronary buttons and aortic sinuses up to a remnant of 2 to $3 \mathrm{~mm}$ were excised. The hypertrophic muscle at the LVOT was excised to release the obstruction. Attention was paid to leave $3 \mathrm{~mm}$ of muscle beneath the aortic valve for placement of a proximal horizontal mattress suture. A 28-mm graft was implanted for root reconstruction. The ascending aorta was replaced with an additional 26-mm graft for creation of a sinus of Valsalva. Another 26-mm prosthesis was implanted between the right ventricle and the translocated pulmonary artery bifurcation to restore the native great artery relationship. The clamp time was 300 minutes, and the bypass time was 423 minutes.

Intraoperative transesophageal echocardiographic analysis showed trivial aortic regurgitation and no LVOT or right ventricular outflow tract obstruction. The postoperative course was uneventful, except for delayed sternal closure for 2 days. He was discharged on the 14th day. Postoperative dynamic computed tomographic analysis demonstrated good coaptation of the aortic cusps and a patent LVOT (Figure 2).

\section{DISCUSSION}

The valve-sparing procedure was sometimes applied in the pediatric group, such as those with tetralogy of Fallot ${ }^{4}$ and patients undergoing the Ross procedure. It has been reported also in a patient with late aortic regurgitation after the Mustard procedure. ${ }^{4}$ We used the valve-sparing operation for the boy because of his relatively small body surface and the potential of better exercise. 

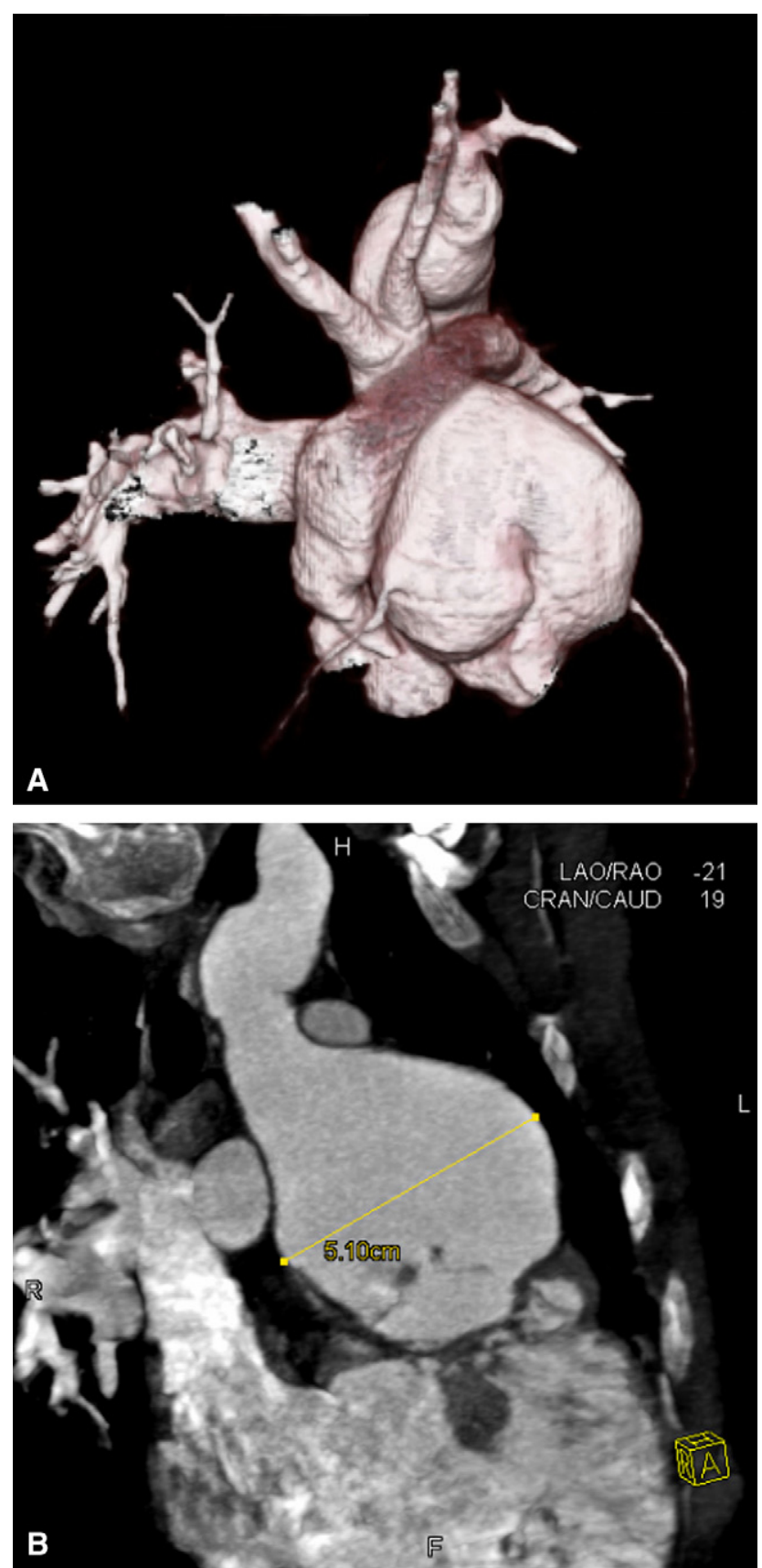

FIGURE 1. A, Dilated ascending aortic root and distorted left pulmonary artery 8 years after the arterial switch operation. Arch coarctation and left and right outflow obstruction were not well demonstrated from this projection. B, The maximal size of the ascending aorta was $5.1 \mathrm{~cm}$.

Because the size of the neopulmonary artery was adequate for this boy, we performed the Lecompte maneuver to restore the spiral relationship and implant a shorter prosthesis. A

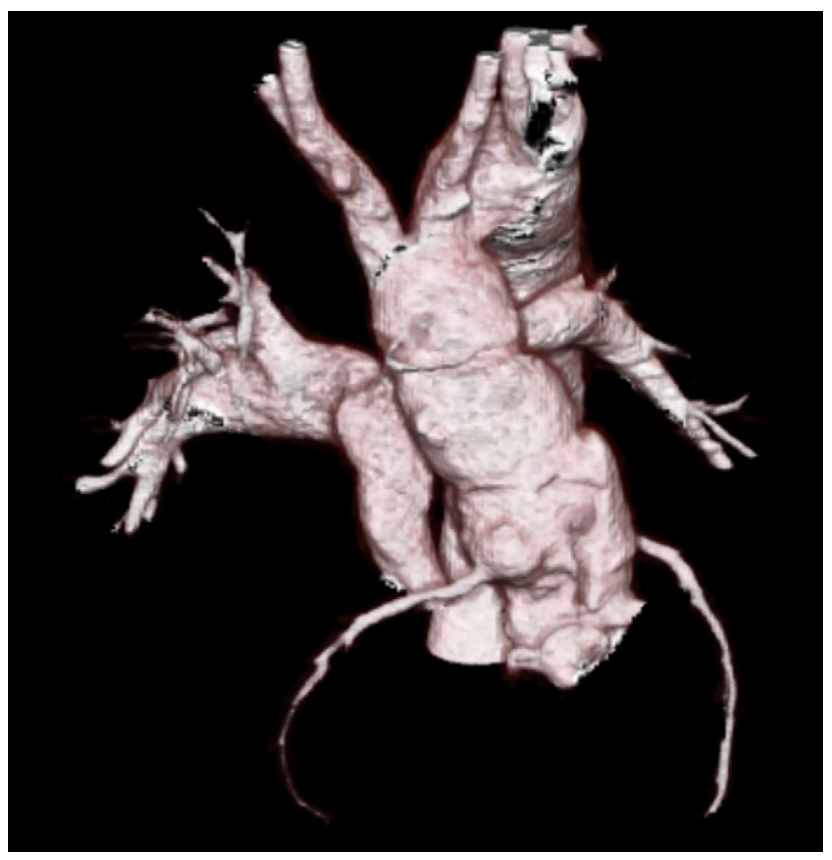

FIGURE 2. Restoration of the great artery relationship and the ascending aorta after the valve-sparing operation. The effect of size reduction of the aortic sinus of Valsalva with minimal regurgitation was also shown.

previous study also demonstrated better fluid dynamics in a native great artery model. ${ }^{5}$ We believed that the valvesparing operation and restoration of the great arteries might offer a more physiological hemodynamic status, despite the long-term effect remaining unknown.

According to our present experience, it is feasible to apply a valve-sparing operation and the Lecompte procedure in patients with the late complication of Taussig-Bing anomaly after the ASO.

\section{References}

1. Losay J, Touchot A, Capderou A, Piot JD, Belli E, Planche C, et al. Aortic valve regurgitation after arterial switch operation for transposition of the great arteries: incidence, risk factors and outcome. J Am Coll Cardiol. 2006;47: 2057-62.

2. Schwartz ML, Gauvreau K, del Nido P, Mayer JE, Colan S. Long-term predictors of aortic root dilation and aortic regurgitation after arterial switch operation. $\mathrm{Circu}$ lation. 2004;110(suppl II):II128-32.

3. David TE, Feindel CM. An aortic valve-sparing operation for patients with aortic incompetence and aneurysm of the ascending aorta. $J$ Thorac Cardiovasc Surg. 1992;103:617-22.

4. Ono M, Goerler H, Kallenbach K, Boethig D, Westhoff-Bleck M, Breymann T. Aortic valve-sparing reimplantation for dilatation of ascending aorta and aortic regurgitation late after repair of congenital heart disease. J Thorac Cardiovasc Surg. 2007; 133:876-9.

5. Tang T, Chiu IS, Chen HC, Cheng KY, Chen SJ. Comparison of pulmonary arterial flow phenomena in spiral and Lecompte models by computational fluid dynamics. J Thorac Cardiovasc Surg. 2001;122:529-34. 